\title{
Motor vehicle occupant injuries in children 2 years and younger: a comparison between Western Australia and New South Wales 1982-92
}

\author{
Mark Stevenson, Peter Palamara
}

\begin{abstract}
Objectives-To compare the age specific rate of passenger injury and associated restraint use for children 2 years and younger in the state of Western Australia (WA), with the state of New South Wales (NSW), Australia for the period 1982-92.

Setting-The states of WA and NSW, Australia.

Methods-A descriptive retrospective study of child passenger injuries in WA and NSW was conducted for the period 1 January 1982 to the 31 December 1992. The data provided information about the injured child, such as sex and restraint use, the driver, vehicle, and collision factors, such as time and posted speed limit.

Results-A total of 2280 children aged 0 to 2 years were injured in motor vehicle collisions during the study period. Of these children, 653 were from WA and 1627 from NSW. Both the injury and mortality rates were higher in WA-compared with NSW over the study period. However $80 \%$ and $79 \%$ of child passengers injured in WA and NSW, respectively, were restrained at the time of injury. Thus both the sex of the driver and the year the motor vehicle was manufactured best predicted the likelihood of a child being restrained.
\end{abstract}

Conclusions-As at 1992, WA's population age specific passenger injury rate for children 0-2 years was more than twice the rate in NSW. The comparable rate of reported restraint use by injured children 0-2 years in WA and NSW suggests that non-use of restraints cannot be singled out as the most likely cause of WA's comparatively high rate of injury. It is difficult to determine whether the disparity in rates could be explained by the child passenger's exposure to crash risk factors, as little is known about child passenger levels of exposure to these factors. Further research is needed to address this issue.

(Injury Prevention 1995; 1: 245-248)

Keywords: child passenger, child restraint, regional comparisons, children under 2 years.

Fatal and non-fatal injuries are recognised as a major health and economic problem in Aust- ralia. Fatal injuries accounted for $3.8 \%$ of all deaths in Australia in $1992^{1}$ with a rate of $42 \cdot 8$ deaths $/ 100000$ population. ${ }^{2}$ The economic significance of injury in Australia is most readily appreciated when the rate of premature mortality is considered. For 1991, the years of potential life lost due to injuries was 865 years/100 000 population. ${ }^{1}$

Of the many causes of fatalities, road traffic injuries remain a major cause of death and years of potential life lost, despite the $49 \%$ reduction in fatalities since $1970 .{ }^{3}$ Road traffic injuries are the leading cause of death by injury for persons aged between 1 and 44 years. ${ }^{1}$ The loss of life in these age groups is of concern. However, it is the premature death of children from traffic injuries that requires the most urgent attention. Children, especially very young children, are neither physically, cognitively, nor socially well equipped to appreciate or deal with threats posed by the road traffic environment ${ }^{45}$ and of the various child road user groups, motor vehicle passengers are at greatest risk. It is estimated that approximately $60 \%$ of those 16 years and younger killed on the road are motor vehicle passengers. $^{3}$

One measure that has repeatedly been demonstrated to be effective in reducing the incidence and severity of injuries to passengers is the use of an approved motor vehicle safety restraint. It has been estimated that the use of safety restraints can reduce the likelihood of death in a crash by up to $50 \%{ }^{6}$

Legislation relating to the restraint of child motor vehicle passengers was first enacted in the state of Victoria, Australia, in 1976, about five years after the introduction of adult seat belt laws. By 1982 all Australian states and territories had passed legislation specific to the restraint of child passengers. ${ }^{2}$ At the time this study was undertaken, however, under the legislation in the state of Western Australia (WA), child passengers were able legally to travel unrestrained if they were younger than 1 year (the only state in Australia where this was permissible) or if they were occupying an unbelted seating position and no other belted position in the rear of the vehicle was available.

While there are other factors beside restraint use that may contribute to a child's risk of injury in the event of a collision, for example vehicle mass and the severity of the collision, restraint use remains the most important means by which drivers can minimise their child passengers' risk of injury. As knowledge of children's exposure levels to such factors is virtually unknown, restraint use must be accepted as an interim, though insufficient, 
measure of children's risk of injury in the event of a collision.

Because of the legislative differences described above, the objective of this study was to compare the age specific rate of passenger injuries (fatal and non-fatal) and associated restraint use for children 2 years and younger in WA with the state of New South Wales (NSW), Australia, for the period 1982 to 1992 .

\section{Methods}

The data were obtained from two sources - in WA from the Police and Main Roads Departments' ROTARS database, and in NSW, from the Roads and Traffic Authority. Each database provides a comprehensive record of all reported fatal and non-fatal motor vehicle collisions, including information about the casualty (such as sex and restraint use), the driver (age, sex), the vehicle (type, year manufactured) and collision factors, such as time, posted speed limit, and collision location. The analyses are for the age group 0 to 2 years for the period 1 January 1982 to the 31 December 1992.

The Pearson $\chi^{2}$ test was used to determine differences between the various proportions, using SAS software. ${ }^{8}$ Injury and mortality rates, and the respective $95 \%$ confidence interval (CI), were reported for both states, using the age specific population estimates from the Australian Bureau of Statistics for $1987^{\circ}$ as the denominator.

The relationship between 15 variables (five main effects and 10 two way interactions) and child restraint use was examined using unconditioned logistic regression on EGRET software. ${ }^{10}$ These variables measured features predicting the likelihood of an injured child being restrained while travelling in a car. The restraint mechanism referred to in this study is a child car seat. There were insufficient data to model restraint use for WA separately because restraint use by injured occupants had only been recorded since 1989. Consequently, the data sources for WA and NSW were combined, and restraint use by injured child occupants was modelled for the period January 1989 to December 1992.

\section{Results}

A total of 2280 children aged 0 to 2 years were injured in motor vehicle collisions between the 1 January 1982 and the 31 December 1992. Of these, 653 were from WA and 1627 from NSW.

Fifty one per cent of the injured in WA and NSW were males. In WA, the driver of the vehicle in which the young child was travelling was predominantly female $(62 \%)$ and aged between 20 and 29 years $(56 \%)$. In 1991 approximately $45 \%$ of women were aged 20 to 29 years, ${ }^{11}$ suggesting that women in this age group may be over represented in these injuries. In contrast, the drivers in NSW tended to be male $(52 \%)$, although they were predominantly $(51 \%)$ in the same age range as the women, 20 to 29 years. The child was a passenger in a standard passenger vehicle
(WA $=93 \%$, NSW $=90 \%$ ) when injured, but the age of the vehicle was significantly older in WA compared with NSW $\left(\chi^{2}=10 \cdot 68, \mathrm{df}=4\right.$, $\mathrm{p}=0.030$ ). In fact, $68 \%$ of the WA motor vehicles involved in the collision were manufactured before 1979 .

The majority of the motor vehicle collisions in WA that involved a child 2 years and younger occurred in urban $(86 \%)$ rather than rural $(14 \%)$ locations. A rural location was defined as any locality with fewer than 1000 occupants (WA Police Department, 1990). In contrast, predominantly all NSW collisions occurred in urban locations $(98 \%)$. Most of the collisions, both in WA (66\%) and NSW (61\%), occurred in areas with posted speed limits of less than $80 \mathrm{~km} /$ hour.

Temporal variations do not appear to explain the incidence of these motor vehicle collisions. Most injuries occurred between $3 \mathrm{pm}$ and $7 \mathrm{pm}$ in both WA (33\%) and NSW (31\%).

Eighty per cent $(n=201$, total injuries, $\mathrm{n}=252$ ) of the child passengers injured in car collisions in WA, since 1989, were restrained. Likewise, since 1989 in NSW, 79\% $(n=337$, total injuries, $n=427$ ) of child passengers were restrained at the time of the collision. No significant difference between restraint use and the state was evident $\left(\chi^{2}=0.029, \mathrm{df}=1\right.$, $p=0.865)$.

To ensure comparabilities of data sources, the severity of injury was classified into deaths, hospital admissions, and those only requiring medical treatment. In WA, 55\% $(n=357)$ of the child passenger injuries required medical treatment, $13 \%(n=83)$ were admitted and $4 \%(n=24)$ died as a result of the injuries sustained (no classification of the severity of the injury was provided for the remaining $28 \%$ $(n=189$ ) of cases). Although the proportion of child passengers 2 years and younger who died as a consequence of the collision is the same in NSW $(4 \%, n=65)$ as in WA, significantly more child passengers in NSW required hospital admission $(22 \%, \mathrm{n}=365)$ or medical treatment $(71 \%, \mathrm{n}=1159)$ compared with WA $\left(\chi^{2}=14.75, \mathrm{df}=2, \mathrm{p}=0.000\right)$.

The incidence of injury in children was also substantially higher in WA over the 11 years, compared with NSW (fig 1). In fact, in WA, the incidence of injury has remained relatively stable over the 11 year period, while in NSW a decline in incidence is evident.

A similar trend is evident when child passenger fatalities in WA between 1982 and 1992 were compared with NSW. The number of deaths in WA fluctuated over the period, while in NSW there was a distinct decline in deaths (see fig 2). The highest fatality rate in WA over the 11 year period was in 1992, with eight deaths $/ 100000$ (95\% CI 2.4 to $22 \cdot 1$ ), while for the same year in NSW, $1 \cdot 1$ deaths/ 100000 (95\% CI $0 \cdot 2$ to $4 \cdot 7)$ were observed.

An unconditional logistic regression model was used to determine which factors best predicted restraint usage (use $v$ non-use). The table shows that the likelihood of an injured child being restrained was influenced independently by the sex of the driver and the year the car was manufactured. Women drivers 


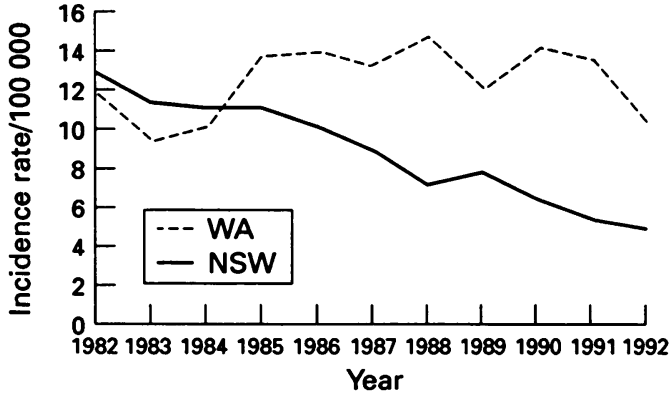

Figure 1 Morbidity rates for $W A$ and NSW child passenger motor vehicle injury, 1982-92.

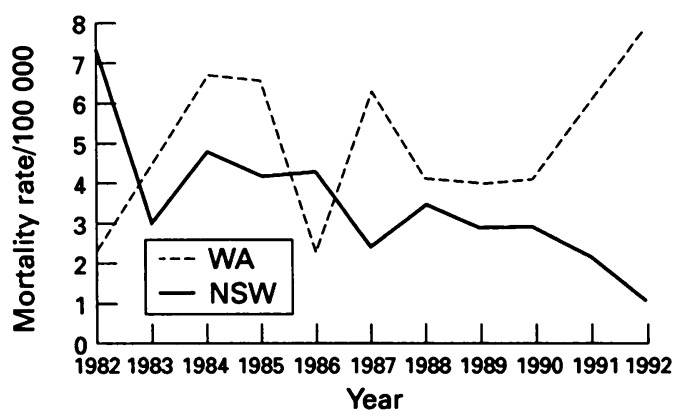

Figure 2 Mortality rates for $W A$ and NSW child passenger motor vehicle injury, 1982-92.

were more likely to restrain their child than male drivers (odds ratio $0.50,95 \%$ CI 0.38 to 0.64 ), while injured child passengers were less likely to have been restrained while travelling in cars manufactured before 1970, compared with passenger injuries incurred when children were travelling in later model cars. In relation to this last point, there was a linear relationship between the likelihood of the child passenger being restrained and the year the motor vehicle was manufactured.

\section{Discussion}

These results indicate that the age specific rate of reported passenger injury among children $0-2$ years of age in WA has remained relatively stable over the period 1982-92. In contrast, the rate of injury for the same age group in NSW over the period has progressively declined. As at 1992, WA's population age specific passenger injury rate for children $0-2$ years was more than twice the rate for NSW.

The disparity between these is amplified further when the age specific fatality rate is considered. The rate for WA shows considerable fluctuation over the study period, whereas NSW's fatality rate has steadily dec-

Factors that predict the likelihood of child restraint use

\begin{tabular}{|c|c|c|c|c|c|}
\hline Variable & Coefficient & $S E$ & Odds ratio & $95 \% C I$ & $\begin{array}{l}\text { Likelihood ratio test } \\
\text { (p Value) }\end{array}$ \\
\hline $\begin{array}{l}\text { Sex of driver } \\
\text { Male } \\
\text { Female }\end{array}$ & -0.688 & $\overline{0} \cdot 131$ & $\begin{array}{l}1.00 \\
0.50\end{array}$ & $\overline{0.38}$ to 0.64 & $28.66(0.000)$ \\
\hline $\begin{array}{c}\text { Year of vehicle } \\
\text { After } 1980 \\
1970-79 \\
\text { Before } 1970\end{array}$ & $\begin{array}{l}\text { e manufactu } \\
\overline{0} \\
0 \cdot 460 \\
0.848\end{array}$ & $\begin{array}{l}\overline{0} \\
0 \cdot 197 \\
0 \cdot 310\end{array}$ & $\begin{array}{l}1.00 \\
1.58 \\
2.33\end{array}$ & $\begin{array}{l}- \\
1.06 \text { to } 2.35 \\
1.27 \text { to } 4.28\end{array}$ & $8.674(0.013)$ \\
\hline \multicolumn{6}{|c|}{ Deviance $=1583.0, \mathrm{df}=1875$} \\
\hline
\end{tabular}

lined (by $85 \%$ ) since 1982. As of 1992, WA's population age specific passenger fatality rate for children 0-2 years was nearly seven times that of NSW.

The comparable rate of reported restraint use by injured children 0-2 years in WA and NSW between 1989 and 1992 suggests that non-use of restraints cannot be singled out as the most likely cause of WA's comparatively high rate of injury among child passengers. The observed restraint use rates in this study are somewhat higher than the rate of $73 \%$ recorded for all Australian child passenger fatalities in $1988 .{ }^{12}$ It must be remembered that the records of restraint use by injured child passengers in WA is only for the period 1989-92. Furthermore, the level of non-use in both states was most likely higher than that reported, as police are known to over estimate the use of restraints among injured occupants. ${ }^{13}$

Despite the fact that the effectiveness of restraint use is known to be moderated by other risk factors such as the type of collision, vehicle mass, and seating position, the question remains why $20 \%$, and possibly more, of the injured children in this study were observed not to be using a restraint. Whether they were unrestrained because a restraint was not available is open to speculation. Unfortunately, the databases do not record the availability of restraints. The logistic regression of restraint use by injured children, however, produced two significant predictors of restraint use, one of which could be viewed as a proxy measure of their availability. A point to note also, is that there are no differences in the types of restraints available in NSW and WA. ${ }^{14}$

The linear relationship found between the date of manufacture of the collision vehicle and reported restraint use by the injured child is of great interest. Children injured while travelling in a vehicle manufactured before 1970 were more than twice as likely not to be restrained compared with children injured in a vehicle manufactured after 1980 . One possible explanation for this finding in pre-1970 vehicles could be the lack of adult belts in the back seat (introduced in 1971) and the absence of anchorage points for fitting specialised child restraints (introduced in 1976). Nevertheless it is difficult to conclude that children travelling in cars manufactured before these dates have a higher exposure to the risk of injury in the event of a collision. General estimates from 1990-1 of the availability of a restraint for use by children in WA who were observed to be unrestrained vary between $74 \%$ and $98 \% .{ }^{15} 16$ It appears most likely, therefore, that children who are not restrained are mostly those who fail to use a restraint that is available.

The other significant predictor of recorded restraint use by injured child passengers was the sex of the driver. The finding that female drivers were twice as likely as male drivers to restrain their injured child passengers supports previous research findings. For example, Palamara found that males were more likely than females to be drivers of vehicles in which at least one child under 14 years of age was observed to be unrestrained..$^{15}$ Research in 
other areas has also demonstrated that, on average, men are greater risk takers and less conservative in their perceptions of risk than women. ${ }^{17}$ Alternatively, it may be that male drivers lack the skill to get children to use restraints or maintain restraint use. Work in progress (PP) suggests that drivers of restrained and unrestrained children differ in their judgments of the difficulty of getting children in to a restraint or maintaining them in it.

As no interaction between the sex of the driver and the date of vehicle manufacture was found for restraint use, there is little reason to believe that the effect of sex on restraint use is due to an increased likelihood of males driving older vehicles that lack restraints.

The above discussion has focused mainly on factors contributing to the risk of injury for child passengers in the event of a collision, particularly the use of restraints, in an effort to explain the reported differences. The other area of risk exposure that must be considered concerns the passenger's exposure to crash risk factors.

It is uncertain whether differences between WA and NSW in the incidence of fatal and non-fatal injury among passengers $0-2$ years can be linked to differential rates of exposure to these risks. Unfortunately, little is known about child passenger levels of exposure to factors such as speed, driver characteristics (blood alcohol level, fatigue, gender, age, skill) road type, road worthiness of vehicles, duration of travel, and the volume of traffic.

Research indicates that male drivers between 17-29 years are over represented in vehicle crashes, particularly those involving speed..$^{18}$ It is unlikely that this factor has had a bearing on the involvement of children 0-2 years in WA in collisions as the results show that most were passengers in cars driven by females aged 20-29 years. This finding may reflect the fact that women spend more time than men transporting very young children in WA.

The advantage of using these databases was that they were easily accessible. Nevertheless, there are problems associated with them. The first is the likely under reporting of injuries. If the police do not attend the collision, or if no medical treatment is required, it is likely that the collision will not be reported. This is the case in $10 \%$ of serious injuries and $33 \%$ of minor injuries. ${ }^{20}$ When the reporting rates of injury deaths in 1992 from the two data sources were compared with the rate in 1992 from the National Minimum Data Source (which is based on coroners' records and deaths registry, $\left.{ }^{21}\right)$ no under reporting was evident in the NSW data source while approximately $10 \%$ of cases were under reported in WA. Consequently, this should be taken into consideration when interpreting the results. Further, it is likely that reporting bias in relation to whether the injured child was restrained at the time of collision may affect the conclusions.

Numerous factors independently or interactively contribute to the likelihood of vehicle crashes and injury. Knowledge of the level of exposure of WA child occupants (aged 0-2 years) to these factors remains minimal. The limitations of the WA injury database, and the limited survery information on the use of restraints by children under 12 months of age in WA, make it difficult to determine the extent to which the rate of injury and reported restraint use among injured children $0-2$ years in WA can be linked to the absence of legislation for infants. Intuitively and logically, however, this explanation seems most likely.

\section{Implications for prevention}

Since this research was undertaken, legislation has been passed in WA that makes it illegal for all motor vehicle occupants, including those 12 months or younger, to travel unrestrained. However, the efficacy of legislation depends on adequate enforcement. ${ }^{22}$ Currently, we have no means of determining the extent to which the legislation is being enforced. It is necessary, therefore, that a system of monitoring enforcement by annual reviews of infringement notices to drivers, for example, be implemented.

The authors wish to thank the Royal Automobile Club of WA and the Child Accident Prevention Foundation of Australia (WA) for funding this research.

1 Australian Bureau of Statistics. Causes of death. Canberra: Australian Bureau of Statistics, 1992. (Cat No 3303.0.)

2 Harrison J, Cripps R. Injury mortality Australia 1992. Australian Injury Prevention Bulletin 1994; 6.

3 Federal Office of Road Safety. Road fatality statistics Aust ralia. Canberra: Federal Office of Road Safety, 1993.

4 Maddux J, Roberts M, Sledden E, Wright L. Developmental issues in child health psychology. Am Psychol 1986; 41. tal issues.

5 Chisholm R. Preventing accidents to children: a study in law and policy. Sydney: Allen and Unwin, 1987.

6 Wagenaar A, Maybee R, Sullivan K. Mandatory seat belt laws in eight states: a time series analysis. $\mathcal{F}$ Safety $R e$ 1988; 19: $51-70$.

7 National Roads and Motorists Association. Road safety milestones. Sydney: Booth Printing, 1988.

8 SAS Institute. Statistical analysis system (SAS computer program). Cary, North Carolina: SAS Institute Inc, 1990.

9 Australian Bureau of Statistics. Estimated resident population by sex and age, States and territories of Australic 1987-1992. Canberra: Australian Bureau of Statistics, 1993.

10 Statistics and Epidemiology Research Corporation Epidemiological graphics, estimation and testing (EGRET computer program). Seattle, Washington: Statistics and Epidemiology Research Corporation, 1993.

11 Australian Bureau of Statistics. Summary characteristics of persons and dwellings. Western Australia. Canberra: Australian Bureau of Statistics, 1991. (Cat No 2482.0.)

12 Attewell R, Dowse M. Fatal crash types: analysis of 1988 fatality file. Canberra: Federal Office of Road Safety, Department of Transport and Communications, 1989.

13 Fildes B, Lane J, Lenard J, Vulcan A. Passenger cars and occupant injury. Canberra: Federal Office of Road Safety,

14 Henderson M. In-depth study of crashes where child occupants are injured: a review of the literature. Sydney: Michael Henderson Research, 1992.

15 Palamara P. An evaluation of a campaign to promote the use of motor vehicle safety restraints by children. Perth: Curtin University of Technology, 1990.

16 Squire D, Maisey G. Restraint wearing rate of vehicle occupants in regional centres of Western Australia. Perth Research and Statistics Unit, WA Police Department 1991.

17 Atkinson R. Introduction to psychology. San Diego, California: Harcourt Brace Jovanovich Publishers, 1990.

18 Haworth N, Rechnitzer G. Description of fatal crashes involving causal variables. Canberra: Federal Office of Road Safety, Department of Transport and Communications, 1993.

19 Adena M, Anderson P, Monstein H. Trends in road crash rates summary report: Australia 1970-1990. Canberra: Federal Office of Road Safety, Department of Transport and Communications, 1993.

20 Bull JP, Roberts BJ. Road accident statistics: a comparison of police and hospital information. Accid Anal Prev 1973; 5: 45-53.

21 National Injury Surveillance Unit (NISU). National minimum data source - injury deaths Australia,

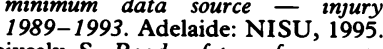

22 Leivesly S. Road safety enforcement: a literature review. Canberra: Federal Office of Road Safety, Department of Transport and Communications, 1985. 